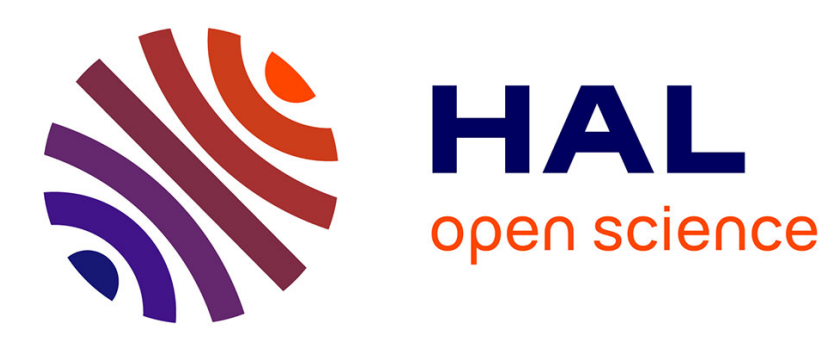

\title{
Endogenous Leadership Selection and Influence
}

Emrah Arbak, Marie Claire Villeval

\section{To cite this version:}

Emrah Arbak, Marie Claire Villeval. Endogenous Leadership Selection and Influence. 2007. halshs00142461

\section{HAL Id: halshs-00142461 https://shs.hal.science/halshs-00142461}

Submitted on 19 Apr 2007

HAL is a multi-disciplinary open access archive for the deposit and dissemination of scientific research documents, whether they are published or not. The documents may come from teaching and research institutions in France or abroad, or from public or private research centers.
L'archive ouverte pluridisciplinaire HAL, est destinée au dépôt et à la diffusion de documents scientifiques de niveau recherche, publiés ou non, émanant des établissements d'enseignement et de recherche français ou étrangers, des laboratoires publics ou privés. 


\section{DOCUMENTS DE TRAVAIL - WORKING PAPERS}

W.P. 07-07

\section{Endogenous Leadership \\ Selection and Influence}

Emrah Arbak, Marie-Claire Villeval

Mars 2007

GATE Groupe d'Analyse et de Théorie Économique UMR 5824 du CNRS

93 chemin des Mouilles - 69130 Écully - France

B.P. $167-69131$ Écully Cedex

Tél. +33 (0)4 72866060 - Fax +33 (0)4 72866090

Messagerie électronique gate@gate.cnrs.fr

Serveur Web : www.gate.cnrs.fr 


\title{
ENDOGENOUS LEADERSHIP
}

\section{SELECTION AND INFLUENCE}

\author{
Emrah Arbak* and Marie-Claire Villeval*\#
}

26 March 2007

\begin{abstract}
In social dilemmas, leading a team by making heroic efforts may prove costly, especially if the followers are not adequately motivated to make similar sacrifices. Attempting to understand what motivates these seemingly selfless individuals to lead, we report the results of a two-stage public good experiment with endogenous timing. Even though it turns out to be costly on average, a large proportion of our subjects volunteer to lead. Our findings suggest that a fraction of these leaders are socially concerned, while others expect to distill some personal gain, possibly of non-pecuniary nature. The composition of the team also matters, as publicizing certain attributes of a subject's teammates has an impact on her decision to lead. Lastly, though voluntary leaders improve efficiency in their team, they are not necessarily more influential than randomly imposed leaders.
\end{abstract}

*CNRS-GATE, University of Lyon. Email: arbak@gate.cnrs.fr

*\# Corresponding author. CNRS-GATE, University of Lyon, France, and Institute for the Study of Labor (IZA), Bonn, Germany.

CNRS-GATE, 93, chemin des Mouilles 69130 Ecully, France. Email: villeval@gate.cnrs.fr. Tel: +33 4728660 79. Fax: +33 472866090.

JEL-Codes: M54, J33, A13, C92, D63

Keywords: Leadership, Endogenous Selection, Influence, Voluntary Contribution, Experiment.

Acknowledgements: We are grateful to C. Plott, D. Friedman, R. Sugden, D. Engelman, H.T. Norman, D. Zizzo, M. Muendler, and participants at the workshop on Communication and Incentives at the University of California in Santa Barbara, the Economic Science Association meetings in Atlanta and Nottingham, the conference of the Association for Public Economic Theory in Hanoi, the Conference on the Analysis of Firms and Employees in Nurnberg. The paper has also benefited from comments during seminar presentations at Royal Holloway University, East Anglia University, University of Rennes. We also thank J. Rossier, A.-R. Blais and F. Martinez for their help regarding the psychological questionnaire and R. Zeiliger for programming the experiment presented in this paper. This research was supported by grants from the Rhône-Alpes Region (Cible program) and from the French Ministry of Research (ACI program). 


\section{INTRODUCTION}

Among the major commitments to be a leader, Michael C. Jensen insists on the following: "Be committed to delaying gratification"(Jensen, 2005), adding that, "the message is the same as that for physical conditioning, no pain, no gain." (Ibid, p.3). Leadership, which typically differs from hierarchical authority, certainly requires energy and patience, but above all, it often requires self-sacrifice, since it is not always associated with personal pecuniary gains. Yet, voluntary leadership is frequently observed in various forms, such as in work teams, public research institutes, classrooms, and associations. A natural question thus arises: If leading is costly, why are some people willing to pay the price?

In this paper, we study the motivations guiding the emergence of voluntary leadership and report the results of an experiment based on a two-stage public good game that reproduces the essential features of teamwork within the context of a social dilemma. In order to highlight the motives of leaders, we allow subjects to make a single contribution in one of two stages. Except in a control treatment where the timing is random, subjects are free to identify when they would like to contribute, either in the first stage, before others (as a leader), or in the second stage (as a follower), after having observed any first-stage contribution. Once all contributions are determined, they are made public information among all group members along with each participant's earnings.

Though all participants have the right to volunteer to lead, we allow at most a single participant to emerge as the actual leader of a group. With several volunteers, the actual leader is randomly selected among these candidates. We ask all volunteers to determine how much they would like to contribute if they were leaders. Eliminated candidates are allowed to revise their contributions, after having observed the actual leader's effort just 
like any other follower. This artifact permits us to glimpse into how leader candidates would act as followers, in effect letting us examine their motives more thoroughly.

In this setup, cooperation is voluntary as the leaders lack any coercive or punitive powers. The leader's earnings are directly linked to how much she can inspire others to contribute. We deliberately consider a simple linear public good game where self-oriented subjects would choose to free ride by contributing nothing to the public account, in order to distinguish between different explanations. Indeed, using a timing game similar to ours, Varian (1994) hypothesizes that those who value the public good least would have an incentive to move first by making small contributions, transferring the burden of funding the public good to the more concerned followers. Therefore, self-interested subjects are expected to have low levels of contributions in either role.

Leading may also be motivated by a subject's social orientation. For example, altruists may be willing to lead and sacrifice their own well-being in order to raise the welfare of others. Andreoni (1990) suggests that seemingly altruistic behavior may also be provoked by positive emotions, i.e. "warm-glow," experienced by publicly contributing to a socially beneficial cause. Furthermore, as all contributions are made public at the end of the game, socially concerned subjects, whether they are leaders or not, may also be willing to teach their teammates that full cooperation is a payoff maximizing strategy. Others, like Glazer and Konrad (1996) and Harbaugh (1998), suggest that large donations in the PG game may be credible demonstrations of an individual's underlying characteristics such as status.

The previous discussion reveals that being a leader or a follower should have little or no impact on the amount contributed by those who are completely self absorbed, altruistic, concerned with the group outcome, or those who simply want to show off. However, 
opportunistic subjects may have an incentive both to pose themselves as leader candidates and to revise their contributions downwards when rejected. Indeed, Huck and Rey-Biel (2006) suggest that leadership may arise endogenously if some agents dislike effort differentials and have a preference to conform. The expectation that followers will conform to generous initial contributions, as first proposed by Sugden (1984), may also appear attractive to opportunistic individuals. Similarly, some individuals may value being influential, or having a positive personal impact in one's own group (Duncan, 2004). ${ }^{1}$ Whether they are guided by opportunism or a taste for influence, these subjects should contribute more as leaders than as followers.

The first contribution of our paper is to analyze the emergence of leadership in an endogenous timing game and to identify its cost. We also search for evidence of various types of motivations in the decision to lead, without pretending to weigh their importance. Notably, this is facilitated by studying how leader candidates respond to being eliminated.

A second contribution of our work is to analyze whether the self-selection of leaders is better predicted by the subjects' inherent characteristics or by their environment. The first alternative refers to the psychological theory of traits (Terman, 1904; Cowley, 1931; Judge et al., 2002). The second alternative focuses on the interactions between subjects and refers to the behavioral theory of leadership (Bass, 1985; Burns, 1978). In our Attribute treatment, subjects are informed about the gender and charitable behavior of their team members before deciding on moving or waiting. By comparing the Benchmark and Attribute treatments, we examine whether making these attributes visible conditions the decision to lead. In addition, we administered the Five-Factor Personality Inventory Test, which allows us to correlate the decision to lead with the personality of the subjects. 
A third contribution of our paper is related to the impact of voluntary leadership on efficiency. On the one hand, those who choose to lead voluntarily are probably more intrinsically motivated to contribute than random leaders, possibly resulting in higher own contributions and stronger influence on followers. On the other hand, the sorting effect of voluntary leadership may be such that pro-social subjects constitute a lower proportion of followers than when roles are allocated at random. By comparing our benchmark with the Imposed-leader treatment, in which the leader is chosen randomly, we aim to determine which effect dominates and which organizational design generates the highest efficiency.

Our paper constitutes the first attempt to empirically investigate the motives underlying the self-selection of leaders in public good games, with a control for personality characteristics and an analysis of the leaders' influence controlling for the endogeneity of the leader's selection.

Our main findings are that a high proportion of subjects are willing to lead although leading turns out to be costly on average. The timing decision is influenced by the subjects' gender, generosity and openness, but other personality factors have no significant predictive power. Donations seem to be interpreted as a signal of subjects' willingness to contribute. Therefore, context matters since being surrounded with generous subjects seems to enhance a subject's own willingness to be the leader and to contribute more. We also provide evidence of the heterogeneity of motives. Notably, using a cluster analysis, we distinguish between selfish, opportunistic, and socially oriented leaders. Moreover, among all leader candidates who were rejected, males seem to be more willing to revise their contributions downwards, suggesting that they are either more concerned to maintain a social image of being influential, or more opportunistic, which is less likely as leading 
turns out to be costly on average. Lastly, we confirm that both the presence of a leader and her effort have a strong impact on total contributions in a group. Leadership-by-example can thus support more efficient outcomes as suggested theoretically (Hermalin, 1998; Arce, 2001). Voluntary leaders increase efficiency because they contribute more than imposed leaders. However, due to the sorting effect, they are not necessarily more influential.

The remaining of the paper is organized as follows. Section 2 reviews the related experimental literature. Section 3 details our experimental design and the procedures. Section 4 displays the main results and Section 5 discusses the results and concludes.

\section{RELATED EXPERIMENTAL LITERATURE}

Hermalin (1998) proposes a theory of leadership-by-example in which a leader receives private information regarding the returns from a public good. According to this explanation, the leader signals the state of nature to her uninformed followers. Most experimental research on leadership has focused on such an asymmetric information framework, in which a randomly chosen leader receives private information. These studies have verified the transmission of information between the informed leaders and uninformed followers (Andreoni, 1998; Versterlund, 2003; Potters et al., 2005, 2007; Meidinger and Villeval, 2003; Moxnes and van der Heijden, 2003). One can find other examples of the positive influence of early announcements and contributions on later contributions in the empirical literature on donations, including Silverman et al. (1984), List and LuckingReiley (2002), and Shang and Croson (2007). Testing a sequential public good game with ex ante symmetric information and random leaders, Gächter and Renner (2006) show that leaders act as “belief managers” and exert a long-lasting influence on followers’ beliefs. 
There is no difference between groups with and without a leader in that the same beliefs trigger the same behavior; but in the groups with a leader, the latter shapes the beliefs.

Only a few experiments address the idea of endogenous leadership. In a context of ex ante symmetric information, Gächter and Renner (2005) design a game in which a leader is designated based on his contribution behavior in earlier parts of the game. Efficiency is enhanced when those who were once free-riders are reintroduced as leaders in later stages, since they increase their contributions, possibly anticipating that the followers will reciprocate. Kumru and Versterlund (2005) assign the role of leader based on a subjects' performance in a quiz. They observe that the leader's influence is positively correlated with her status. When some subjects are more informed than others and group members are allowed to vote in favor of either a sequential game with informed leaders or a simultaneous game, Potters et al. (2005) show that most players choose the sequential game, in order to maximize their own welfare. Similarly, Güth et al. (2007) find only $40 \%$ of groups succeeding to appoint a leader, when subjects vote on whether they want a leader or not. Though these studies allow collective decision-making, leaders do not necessarily self-select their roles. Voluntary leadership is clearly an original aspect of our paper.

Our design is closer to endogenous timing games. Huck et al. (2002) investigate a duopoly game in which a firm chooses between moving first or moving after observing the decision of the other firm. Though economic theory predicts the emergence of endogenous Stackelberg leadership, they find that subjects are more willing to settle for Cournot outcomes. Other experimental tests of leadership in duopoly games can be found in Fonseca et al. (2006). Like in these games, our subjects decide to move first or second. In contrast with these studies, we consider a public good game in which economic theory 
predicts that only those who value the public good least, that is self-interested subjects, should move first with no or very little contributions.

\section{EXPERIMENTAL DESIGN AND PROCEDURES}

\section{$\underline{\text { Design }}$}

We use three variants of a simple three-player sequential public good game. Each session consists of 30 periods and subjects are re-matched after each period. At the end of the game, subjects are administered a personality test.

The Benchmark treatment. In the beginning of each period, each of the three group members is endowed with 20 units. This endowment can be used to contribute to a public account or to be kept on a private account. All funds in the public account pay an equal positive return to each member of the group.

The game is two-staged. In the first stage, each group member decides on whether she is willing to lead the group ("to make his contribution decision immediately"). Leading the group means contributing first to the public account and making this contribution visible to the other group members before they make their own contribution decisions. The leader candidate indicates the amount of his contribution. In the second stage, those subjects who chose not to contribute before others (the followers) are first informed about their leader's contribution, if any, and then asked to specify the amount they would like to contribute to the public account simultaneously. The marginal per capita return from a contribution to the public account is 0.5 . The payoff of subject $i$ is therefore given by:

$$
\pi_{i}=20-c_{i}+\alpha \sum_{j=1}^{3} c_{j} \quad \text { with } \alpha=0.5
$$


At the end of each period, the group members are informed about the individual contributions of all members and their personal payoffs.

We do not allow more than one leader to move first. ${ }^{2}$ Given that the decision to lead is made simultaneously, there are three distinct possibilities. If no participant is willing to lead, the three group members are moved directly to the second stage and contribute simultaneously to the public good. In this case, the game is similar to the standard voluntary contribution mechanism game, apart from the fact that the simultaneity is achieved endogenously. If only a single subject is willing to lead, the procedure described above applies. If there are several candidates, a random draw determines the actual leader. Only the contribution of the selected candidate is indicated to others. The first stage contribution of an eliminated candidate is not taken into account. Instead, eliminated candidates are treated like followers and allowed to modify their initial proposed contributions. Keeping track of both the initial proposal and the revised contribution enables us to examine how eliminated candidates adjust their behavior. The experimental setup is made common knowledge in the instructions (see Appendix).

Two additional treatments. Unlike the Benchmark treatment, in which only information regarding the individual contributions was provided, the Attribute treatment aims to study how the contribution and timing decisions are influenced by other characteristics of group members. It replicates the structure of the Benchmark treatment. The only difference is that in the beginning of each period, the subjects are informed about two attributes of their group members that are represented by pictograms on the subjects' screens. The first attribute is gender, which is self-reported by the subject in the beginning of the experiment. The second attribute attempts to measure the social orientation of a subject. ${ }^{3}$ In order to 
proxy social orientation, we allow the subjects to donate real money into a charity. In the beginning of each session after the instructions are read aloud, each subject is given a show-up fee of 6 Euros. Then, subjects are allowed to donate $€ 0$ to $€ 6$ to a charity of their choice. ${ }^{4}$ The difference between the show-up fee and the donation is kept on the subject's account and added to the additional earnings. The information about the subject's donation is displayed as follows. If the subject's donation is above the session average, then a yellow circle identifies her. Otherwise, the subject receives a gray circle. ${ }^{5}$

We are aware that donations are not an exact measure of a subject's social orientation or generosity. Indeed, when they make their donations, the subjects know that this information will be displayed to others during the session. A donation may thus be a strategic decision. That is, a subject may want to donate more simply to trick her group mates to believe that she will contribute generously. However, since the displayed circles identify above or below average donations in any given session, we expect a yellow circle to nevertheless be a relatively good indicator of the subject's above average generosity.

In the Imposed-leader treatment, we select a leader at random among the group members. As before the leader moves first and the others contribute simultaneously after being informed on the leader's contribution. No information about attributes is displayed. While by contrasting the Benchmark and Attribute treatments we investigate the motives behind the self-selection process, by comparing the Benchmark and Imposed-leader treatments, we highlight the impact of voluntary leadership on efficiency. More specifically, we are able to analyze whether a voluntary leader contributes more than a designated one and whether second movers are more willing to follow a voluntary leader. 
The theoretical predictions with selfish subjects are similar in all treatments. The subgame perfect equilibrium is to contribute nothing in the second stage since every individual is better off by keeping his endowment for himself regardless of what the others allocate to the public good, since the marginal return from contributing to the public account is lower than the return from the private account $(\alpha<1)$. In contrast, the efficient outcome is for each subject to contribute all her endowment, since the return when all group members contribute an additional amount is higher than the return from the private account $(n \alpha>1)$.

A personality test. At the end of the session, we administered a personality test to our subjects to investigate whether specific traits distinguish leaders and followers in the endogenous leadership treatments. We used the French version of the Five-Factor Inventory personality test commonly known as the "Big Five" (NEO-FFI) (see Costa and McCrae, 2004; Rolland et al., 1998; Rossier et al., 2003). This test consists of 60 items, presented alternatively in positive and negative phrasing. It is based on voluntary selfassessment. Each subject is given an additional $€ 2$ for having completed the test. Respondents are asked to consider each item and to decide, using a five-point Likert-type scale, whether they agree or disagree with each proposition. These items provide a concise measure of the five dimensions of personality (neuroticism, extraversion, openness, agreeableness and conscientiousness) that summarize the personality of an individual (Costa and McCrae, 1992). ${ }^{6}$

On average, the questionnaire took 15 minutes to be completed. After the validation of the questionnaires, we factored the items for each gender ${ }^{7}$ and computed a t-score for each factor that relates each individual score to the mean and the standard deviation of the 
sample of participants. This allows us to compare directly the scores obtained by males and females and to include them in our econometric analyses.

\section{$\underline{\text { Procedures }}$}

The experiment was computerized by utilizing the REGATE software (Zeiliger, 2000). Sessions were conducted in the experimental laboratory of the Groupe d'Analyse et de Theorie Economique (GATE) in Lyon, France. A total of 141 subjects (72 females and 69 males) were recruited from undergraduate classes in three local engineering and business schools. The subjects had no prior experience with public goods experiments. We ran 8 sessions under a stranger matching protocol. ${ }^{8}$ Each session consisted of three sets of 10 periods alternating between two treatments. The ordering of treatments for each session is detailed in Table 1.

Upon arrival, each subject drew a label from a bag, indicating the name of his computer, and entered the laboratory. The instructions (see Appendix) for the preliminary and the first parts of the session were distributed and read aloud. We added a short description of each of the three humanitarian NGOs and a form to be filled out by the participants requesting a receipt to prove the payment of the total donations to these NGOs. The subjects then filled out a questionnaire enabling to check their understanding of the rules of the game. Questions were answered in private. The subjects could then decide on the amount of their donation to a charity. Once all the subjects entered their decisions, the program matched them randomly. Groups were reshuffled after each period. At the end of the first (second) set of periods, the instructions of the second (third) part were distributed, with no questions allowed. Last, the personality test was administered and a final question was asked about car ownership which answer was used as an (imperfect) index of wealth. ${ }^{9}$ 
An average session lasted about 70 minutes. Each point earned during a session was convertible to Euro at 80 points $=€ 1$. The participants gave on average $€ 1.04$ to a charity . They earned an average $€ 15.70$, corresponding to the sum of the payoff earned in each period and the fraction of the show-up fee they did not donated. An assistant who was not aware of the content of the experiment helped subjects with their donations and payments in private, all of which was made common knowledge in the instructions. This procedure was used to prevent any feeling of shame that could have biased the donation behavior if the payment was to be made in front of the experimentalist who conducted the sessions.

\section{RESULTS}

An overview of our results shows that a substantial proportion of subjects are willing to lead, in contrast with the equilibrium predictions. We first focus on the analysis of the determinants of the leadership decisions and contributions. Second, we examine the behavior of the eliminated leader candidates. Third, we concentrate on the influence of leaders. Lastly, we produce a cluster analysis of the behavior of leaders and followers in order to push further the investigation of the variety of motives for voluntary leadership.

\section{Leaders' behavior}

Before we delve into the leaders' motives, we show that moving first on average entails a loss. Table 2 displays a summary of the descriptive statistics before we present the results of a regression analysis.

Contrary to standard predictions, Table 2 shows that a significant proportion of subjects, roughly a quarter of all participants, are willing to lead voluntarily. Figure 1 displays the evolution of this proportion over time by treatment. 
In the first ten periods, the proportions of subjects who are willing to lead are $33.14 \%$ in the Benchmark treatment and 35.83\% in the Attribute treatment. Although these proportions decline over time, there are still $17.71 \%$ of subjects who are willing to lead in the Benchmark treatment and $21.67 \%$ in the Attribute treatment in the last set of periods. Consequently, $57.42 \%$ of the groups have a leader in the endogenous treatments and this proportion is still $46.38 \%$ in the last set of periods.

Leading voluntarily is common and would not have been too unusual if leaders and followers earned similar amounts. However, our finding is striking since leaders seem to willing to forego expected relative losses from contributing first. A first indication of these relative losses is found in the comparison between leaders' and actual followers' average contributions in groups with a leader. Table 2 indicates that the ratio of average leaders' contribution to followers' contribution is 2.14 in the Benchmark, 2.26 points in the Attribute treatment and 1.92 points in the Imposed-leader treatment. Table 3 shows the evolution of leader candidates' and actual followers' contributions over time and displays the ratios between the two values.

Table 3 indicates that the leaders' contributions decrease less over time than the followers' contributions. The leaders' influence progressively vanishes and they are less and less paid in return for their efforts. A second indication of leadership costs can be found in the analysis of payoffs. As shown by Table 2 and in accordance with the different contribution levels examined above, the leaders earn dramatically less than the followers. The difference is larger when leadership is endogenous. In the Benchmark, a leader earns on average $75 \%$ of the follower's payoff. These values are $74 \%$ in the Attribute treatment and $81 \%$ in the Imposed-leader treatment. 
Being a follower in a group with a leader is clearly preferable, since the average payoffs of these participants is superior to average payoffs in groups without any leader (see Table 2). A simple explanation for why some subjects are willing to bear the cost of being a leader could be that leading is expected to be more profitable than another risky outcome, being in a group without any leader. Our data does not support such a motive. To see this, note that the minimum payoff that a subject can secure is 20 points, which is guaranteed by not contributing into the public account. A quick look at the earnings of leaders in Table 2 shows that average payoffs dip below this threshold in Benchmark and Attribute treatments. Voluntary leaders are getting less on average than the amount they could secure for themselves and they earn slightly less than an average subject without a leader. In the Benchmark and Attribute treatments, the leaders' average earnings are 19.46 and 19.16 points, respectively, while average earnings in groups with no leader are 20.79 and 20.56 points, respectively.

One could object to the previous arguments by saying that they are based on average earnings and may not be valid once subjects have had sufficient time to learn how to play the game. Such an argument also seems to be incorrect. Indeed, if we consider the last set of periods only, being a leader demands even a greater sacrifice. In periods 21 to 30, the difference in payoffs between a leader and any member of a group without a leader is 2.14 points in the Benchmark treatment (instead of 1.32 in the first set of periods) and 1.79 points in the Attribute treatment (instead of 1.21). Even with these differences in sight, a significant proportion of all subjects choose to be a leader.

These statistics confirm that subjects seem to be willing to sacrifice their potential earnings in order to be a leader. The immediate questions to be answered are therefore the 
following: Which subjects accept these potential losses? Which conditions intensify their willingness to do so? And, what do these leader candidates buy?

Determinants of the decision to lead. We study the probability to be willing to lead using random-effects probit models accounting for repeated decisions by each subject. The exogenous variables include a time trend to identify the evolution of leadership probability over time (period). We also include the subject's gender, the amount of points donated to a charity (donation), the t-scores for each personality factor, and a dummy for car ownership to account for wealth effects. The donation variable is interacted with the gender variable for being able to discern the effect of gender on donations (see Eckel and Grossman, 2000). It is also interacted with a dummy indicating whether the benchmark treatment is part of a sequence including the Imposed-leader treatment ("donation*BIB") because in this sequence strategic donations are ruled out. We also include session dummies, the first session being omitted. In the regression for the Attribute treatment, we also add four variables determining the group composition. These variables indicate whether the subject is teamed with two low donors (subjects who gave a donation equal or lower than the average), two high donors (subjects who donated more than the average), two females, or two males. Table 4 reports the estimations for two models; the first model pools data from the endogenous treatments; the second model only considers the Attribute treatment.

We find that the probability to lead is decreasing over time in both estimations. This is consistent with both a learning hypothesis and the previous finding that the relative cost of leading increases over time. Those who donate a larger amount are more likely to be a leader candidate, suggesting that generous individuals are more willing to bear the cost of leadership. Non-strategic donations have no different impact since the coefficient 
associated with the "donation*BIB" variable is not significant. This is consistent with the descriptive statistics indicating that the average donation amounts to 104.49 points among the leader candidates and 79.65 among those subjects who are not candidates.

A quick look into the gender composition of leader candidates shows that males seem more eager to lead than females; $27.46 \%$ of males choose to lead, while the corresponding value for females is only 23.93\%. But this difference vanishes when attributes are made public. The proportion of females who are willing to lead increases from $23.23 \%$ in the Benchmark to $25.61 \%$ in the Attribute treatment. The same proportion for males is constant in both treatments: $27.27 \%$ and $27.83 \%$, respectively. Our regression results reinforce these statistics. Being a male increases the probability to lead significantly, by as much as $10 \%$, when we pool data. Also, the gender difference is no longer significant when we only consider the Attribute treatment. One possible explanation is that females require more information about their group members than males to invest in leadership; that is their contributions tend to be conditional on other aspects of the game. ${ }^{10}$ Females who donate more are also more likely to lead. Then, for females a high donation is more strongly associated with generosity, which has a positive effect on the likelihood of leading. As for males, the descriptive statistics show that donations tend to be more strategic in nature. ${ }^{11}$

We do not find in our data a strong support for the argument that personality factors are good predictors of voluntary leadership. Only openness increases significantly the probability to lead when we pool all endogenous treatments together. The influence of openness is consistent with psychological studies of leadership. Judge et al. (2002) recall that in Bass's (1985) analysis, originality, creativity and non-conformism are the primary predictors of leadership as they are primarily related to openness. 
Last, the estimates of the second model show that subjects condition their decision to lead on some attributes of their group members. Indeed, being teamed with two low donors reduces the likelihood of running for leadership. An explanation is that a low donation is probably taken as a signal of a lower willingness to contribute. The reluctance to be a "sucker" may then reduce the willingness to lead. This impact is not symmetric. Being matched with two high donors does not affect the likelihood to run for leadership. Lastly, the gender composition of the group does not affect the willingness to lead.

Leaders' contributions. We estimate random effect tobit models by considering the first stage contributions of leader candidates as the independent variable and accounting for the left and right censuring of the data. The first model pools the data from all treatments. The second model considers the endogenous treatments and the third one analyzes the Attribute treatment. Table 5 reports the results.

Table 5 shows that imposed leaders contribute less than voluntary leaders, while making the attributes of the team members visible increases the voluntary leaders' contributions. These estimations supplement the simple comparison of the proportions of censured data across treatments. In the Imposed-leader treatment, $24 \%$ of the leaders contribute nothing whereas $22 \%$ contribute their full endowment; the respective proportions are $8 \%$ and $29 \%$ in the Benchmark treatment, and $3 \%$ and $34 \%$ in the Attribute treatment. ${ }^{12}$ The observation that voluntary leaders contribute more than imposed ones can be driven by two reasons. First, less constrained activities may translate into higher efforts (see Falk and Kosfeld, 2006; Eriksson et al., 2006). Second, free riders are sometimes randomly selected as leaders in the Imposed-leader treatment. When personal characteristics of gender and donation level are publicly displayed, voluntary leaders condition their decision to lead on 
their group members' attributes and are therefore inclined to contribute more than when they are hidden.

We find a negative time trend in the three regressions: leaders adjust their contributions downwards over time. We also observe that most personal variables have no significant impact on the leader's contribution, as if the role of a leader subsumed almost all individual characteristics. In contrast, the characteristics of group members have a significant influence on the leader's contribution in the Attribute treatment.

\section{$\underline{\text { Eliminated leader candidates' behavior }}$}

When there are several leader candidates, a random draw eliminates all but one. 25\% (155 out of 463 ) and $26 \%$ (87 out of 249) of all candidates have been eliminated in this manner in the Benchmark and Attribute treatments, respectively. When allowed to modify their initial contributions after observing the actual leader's contribution, 22\% of the eliminated candidates revise their contribution upwards and $41 \%$ revise downwards. This revision possibility enables us to dig deeper into what may motivate them to be a leader. An immediate question is whether the contributions of eliminated candidates are similar to the contributions of self-selected followers. Figures $2 \mathrm{a}$ and $2 \mathrm{~b}$ contrast the contributions of actual leaders, eliminated leader candidates, and self-selected followers for each gender.

These figures reveal that in general eliminated leaders contribute more than three times more than self-selected followers. ${ }^{13}$ Another striking feature of the contributions depicted in Figures 2a and 2b is that in both Benchmark and Attribute treatments, eliminated female candidates contribute almost the same amount as actual female leaders while elimination

seems to have a negative impact on the contributions of male candidates. ${ }^{14}$ However, we need to account for the fact that adjustments may also depend on the actual leader's 
contribution. One would expect that, if the contribution of the actual leader is inferior (superior) to the initial amount put forth by the candidate, then adjustment should be downwards (upwards). We relate (signed) revision decisions to the leader's contribution in Figure 3. A negative value in the figure signifies a downward modification, such that the revised contribution is less than the original one. For each gender, we depict average modifications in response to inferior and superior contributions by the actual leader.

Without any surprise, when the actual leader's contribution is inferior, both males and females reduce their contributions, though the (downward) adjustment appears stronger for males. However, when the actual leader's contribution is superior, females increase their contributions and follow the actual leader while eliminated male leaders slightly decrease their contributions and do not follow the actual leader.

To understand the determinants of the revision of an eliminated candidate's contribution, we first estimate an ordered probit model with robust standard errors, in which the sign of revised amount is the dependent variable, equaling +1 if the revision is upwards, 0 if no revision occurs, and -1 if the revision is downwards. Then, we estimate a GLS model in which the amount of the revision is the dependent variable. We measure the influence of the actual leader, controlling for the usual variables. Table 6 reports these estimations.

Both regressions confirm that the revision is positively influenced by the amount contributed by the actual leader, but that males are less likely to revise their own contribution upwards. This reluctance of males to revise upwards when the actual leader is more generous is probably due to the fact that what motivates males to be a leader is different than what motivates females. The premium that males are willing to pay to lead is less likely to be motivated by a concern for the group’s welfare, for if that was the case, 
males, like females, would be eager to follow the actual leader. This behavior may be explained by one's selfish concern, as the candidate contributes opportunistically to make the followers reciprocate generously, or by the candidate's preference for having a personal impact on the welfare of the group (see Duncan (1994)'s model of impact philanthropy).

\section{The influence of leaders}

Do leaders exert an influence on followers and if so, is this influence stronger when the leadership is voluntary? Influence can be measured in two distinct ways: First, by comparing the average second stage contributions with and without a leader, and, second, by stating the followers’ contributions as a share leaders' contributions. In groups with no leaders, average contributions are 1.84 points in the Benchmark and 1.40 in the Attribute treatment. In groups with a leader, the average followers' contributions are 5.52 points in the Benchmark treatment (+200\%), 5.23 points in the Attribute treatment and 5.03 points in the Imposed-leader treatment (+274\%). This shows that having a leader in a group makes a big difference. We observe that a follower matches $47 \%$ of the leader's contribution in the Benchmark treatment, $44 \%$ in the Attribute treatment and 52\% in the Imposed-leader treatment. The coefficients of pairwise correlations between the second stage contributions and actual leaders' contributions are 0.38 in the Benchmark treatment, 0.33 in the Attribute treatment and 0.48 in the Imposed-leader treatment. This indicates that voluntary leaders do not necessarily exert a stronger influence on their group members.

This is confirmed by a regression analysis of the followers' contributions. We estimate random-effects tobit models in which we include either a variable indicating whether the group has a leader or not (leader in group) or the actual leader's contribution. A dummy indicates whether the subject has been a leader candidate in the current period (eliminated 
leader). We control for the usual variables. In the first estimation, we pool the data from the three treatments and focus on groups with a leader. In the next two estimations, we analyze the data from both endogenous leadership treatments, considering first all groups and then only those with a leader. Table 7 reports these estimations.

The estimations show that the presence of a leader and the seed contribution, whether the role is imposed or not, are all significant determinants of how a follower acts. Although leaders are influential, our first estimation shows that the amount contributed by a follower is not significantly different across treatments. This finding shows that voluntary leaders are not more influential than random leaders. In other words, followers do not reciprocate more when the leader has self-selected. The second and third estimations confirm that in the endogenous leadership treatments, eliminated candidates contribute more than other followers. An additional specification for the sole Attribute treatment (not reported here) finds that the leader's attributes exert no additional influence.

Although voluntary leaders are not more influential than random leaders, they contribute more on average. As a consequence, in groups with a leader the average size of the public good is greater when leadership is voluntarily determined than when it is randomly assigned. On average, the public good amounts to 22.87 points in the Benchmark, 22.29 points in the Attribute treatment and 19.71 points in the Imposed-leader treatment. When there are no leaders, the public good is only 5.51 points in the Benchmark and 4.19 points in the Attribute treatment. Efficiency is thus greater when leadership is voluntary and there is at least one leader candidate. When there are no candidates, designating any team member as a leader is more efficient than letting all subjects contribute simultaneously. 
Heterogeneity of behavior towards leadership

To better understand the diversity of motives behind the decision to lead, we now turn to a cluster analysis. Instead of starting from pre-defined strategies, we derive these strategies from an analysis that allows us to identify homogenous groups of subjects following the same type of behavior. In order to partition the sample, we retain three variables that summarize each individual's decisions in the two endogenous leadership treatments: the relative frequency of the decisions to lead, the average contribution as a leader candidate, the average contribution as a follower. ${ }^{15}$ We obtain four main clusters. Table 8 summarizes the statistics regarding each cluster; for memory, it also reports the average donation but this variable is not active in the identification of the clusters.

Cluster 1 consists of subjects who are less often willing to lead than the rest of the population and who contribute little, both as leaders and as followers. The singularity of this group lies mostly in the average first-stage contribution that only represents $45 \%$ of the average leaders' contribution in the whole population. Cluster 2 consists of subjects who lead almost as frequently as those in cluster 1 , but are characterized both by the maximum first-stage contribution (close to full cooperation) and the minimum second-stage contribution (close to full free-riding) in the population. This cluster groups a very few number of subjects but it is robust to many alternative specifications of the clusters. Cluster 4 is characterized by the highest frequency of the decision to lead (in more than $43 \%$ of the periods), accompanied by a high average first-stage contribution and the highest average second-stage contributions. In this cluster, the average followers' contribution is more than twice as high as that in the whole population. Cluster 3 represents an intermediate category with characteristics close to the averages. 
The vast differences between clusters indicate that there may be several motivations in the decision to lead. Behavior in cluster 1 is close to that predicted by Varian's model (1994). Leaders and followers alike seem to be selfish individuals. As an additional validation of our argument, the average donation in this cluster is low. Having donated the lowest average amount among all four clusters, the subjects in cluster 2 essentially act selfishly by contributing very little, except when offered the opportunity to have a personal impact on the well being of the group. Assuming that they are motivated either by an urge to personally influence others or by opportunism, these subjects are ironically not conditional cooperators themselves. In contrast, the behavior of those in cluster 4 is attributable either to altruism or a strong concern for the group outcome, as these subjects lead often, have above average contributions, either as a leader or a follower, and donate a large portion of their endowments in the beginning of the session.

\section{DISCUSSION AND CONCLUSION}

Informal leadership in groups is frequently observed despite the fact that setting a good example is not necessarily profitable for the leader. We test whether in a social dilemma game, with free-riding as the dominant strategy, voluntary leadership can emerge without any assured benefits or direct communication among participants. Our design allows subjects to choose the timing of their contribution in a linear public good game. Through an artifact, we are able examine how those who show an interest to act first would adjust their contributions when forced to move second. With the aid of various treatments, we determine the influence of group members' characteristics on the decision to lead and we compare the efficiency and influence of voluntary leaders to imposed leaders. 
Our primary finding is that a large proportion of subjects are willing to lead, though they earn on average considerably less than followers and even less than those in a group with no leader. The decision to lead is partially determined by the participant's traits, such as the gender, generosity and openness but personality factors have little further explanatory power. Displaying the donation level of one's group mates has an influence on decision to lead: being matched with less generous subjects reduces one’s willingness to contribute first. We claim that the donation information is used to form beliefs about the likely attitude of others. We also show that in groups with a leader, voluntary leadership improves efficiency since self-selected leaders contribute more than imposed leaders. However, voluntary leaders are not more influential than imposed leaders.

Both the behavior of eliminated leader candidates and our cluster analysis suggest that there may be complementary motives for being a leader and that no single theory is able to explain the decision to lead in a social dilemma game. We identify a fraction of subjects who lead frequently and contribute a large proportion of their endowment. Among these cooperators, altruism is a potential explanation, supported by the positive correlation between the amount of the donation to a charity and the probability to lead. It is also supported by the number of remaining candidates in the last set of periods though the subjects had time to learn the costs of leading. Cooperators may also be people who are concerned by the group outcome and who try to teach others that the payoff maximizing strategy for the group is to coordinate on full cooperation. Both explanations are consistent with the fact that the behavior of eliminated candidates in the second stage is closer to actual leaders' than to self-selected followers' behavior. However, if altruism can explain leading in the last periods, the teaching explanation cannot. 
In contrast with these socially-oriented motivations, our experiment provides evidence for self-interest in the decision to lead. A fraction of subjects move first and free-ride. Selfishness may explain such behavior that gives some support to Varian (1994)'s model. Instead of trying to set an example, by moving first these subjects make it clear that the burden of contributing to the public good is transferred onto the others. Another distinct group of subjects contribute large amounts as leaders but are much less generous as followers. Though we do not identify a large cluster of such behavior, the examination of how eliminated candidates modify their contributions reveals that males are particularly prone to act in this manner. The reason that some subjects are willing to contribute more as leaders may be to trigger followers to contribute large amounts themselves, but this is not very likely in the long run since, as highlighted above, leading turns out to be costly on average. As an alternative explanation, participants may be concerned with maintaining a positive public image by appearing as an influential leader.

These results add to a growing body of experimental research that shows the importance of heterogeneity of types in the dynamics of cooperation (Burlando and Guala, 2005; Kurzban and Houser, 2005; Bardsley and Moffatt, 2005; Gächter and Fischbacher, 2006). Once the role of the type composition of groups has been accounted for, further research is needed to see how the manipulation of group formation could improve the efficiency of leadership. 


\section{REFERENCES}

Andreoni, J., 1990. Impure Altruism and Donations to Public Goods: A Theory of WarmGlow Giving. Economic Journal 100, 464-77.

1998. Toward a Theory of Charitable Fundraising. Journal of Political Economy, 1186-213.

Arce, D., 2001. Leadership and the aggregation of international collective action. Oxford Economic Papers 53, 114-37.

Arrow, K., 1972. Gifts and Exchanges. Philosophy and Public Affairs 1, 343-62.

Bardsley, N., Moffatt, P.G., 2005. The Experimetrics of Public Goods: Inferring Motivations from Contributions. University of Nottingham, CeDEx Discussion Paper, 2005-09.

Bass, B.M., 1985. Leadership and Performance Beyond Expectations. New-York: Free Press.

Bénabou, R., Tirole, J., 2006. Incentives and Prosocial Behavior. American Economic Review 96(5), 1652-78.

Burlando, R.M., Guala, F., 2005. Heterogenous Agents in Public Goods Experiments. Experimental Economics 8, 35-54.

Burns, J.M., 1978. Leadership. New-York: Harper \& Row.

Costa, P.T., McCrae, R.R., 2004. A Contemplated Revision of the Neo Five-Factor Inventory. Personality and Individual Differences 36, 587-96.

, 1992. Revised Neo Personality Inventory (Neo-Pi-R) and Neo Five-Factor Inventory (Neo-Ffi) Professional Manual. Odessa: FL: Psychological Assessment Resources.

Cowley, W.H., 1931. Three Distinctions in the Study of Leaders. Journal of Abnormal and Social Psychology 26, 304-13.

Duncan, B., 2004. A Theory of Impact Philanthropy. Journal of Public Economics 1, 2159-80.

Eckel, C.C., Grossman, P.J., 2000. Differences in the Economic Decisions of Men and Women: Experimental Evidence, in Plott, C. R., Smith, V. L. (Eds.), Handbook of Results in Experimental Economics. New-York: North-Holland,

Eriksson, T., Teyssier, S., Villeval, M.C., 2006. Self-Selection and the Efficiency of Tournaments. IZA Discussion Papers, 1983. Bonn.

Falk, A., Kosfeld, M., 2006. The Hidden Costs of Control. American Economic Review 96(5), 1611-1630.

Fonseca, M.A., Huck, S., Normann, H.T., 2006. Endogenous Timing in Duopoly: Experimental Evidence. International Journal of Game Theory 34, 443-56.

Gächter, S., Renner, E., 2005. Leading by Example in the Presence of Free Rider Incentives. University of Nottingham, CeDEx Discussion Paper.

Gächter, S., Renner, E., 2006. Leaders as Belief Managers for Pro-Social Behavior. University of Nottingham, mimeo.

Gächter, S., Fischbacher, U., 2006. Heterogeneous social preferences and the dynamics of 
free riding in public goods. University of Nottingham, CeDEx Discussion Paper, 2006-01.

Glazer, A., Konrad, K., 1996. A Signaling Explanation to Charity. American Economic Review 86, 1019-28.

Gneezy, U., Niederle, M., Rustichini, A., 2003. Performance in Competitive Environments: Gender Differences. Quarterly Journal of Economics, 1049-74.

Güth, W., Levati, M.V., Sutter, M., van der Heijden, E., 2007. Leading-by-example with and without exclusion power in voluntary contribution experiments. Journal of Public Economics, forthcoming.

Harbaugh, W.T., 1998. What Do Donations Buy? A Model of Philanthropy Based on Prestige and Warm-Glow. Journal of Public Economics 67(2), 269-84.

Hermalin, B., 1998. Toward an Economic Theory of Leadership: Leading-by-Example. American Economic Review 88, 1188-206.

Huck, S., Müller, W., Normann, H.T., 2002. To Commit or Not to Commit: Endogenous Timing in Experimental Duopoly Markets. Games and Economic Behavior 38, 24064.

Huck, S., Rey Biel, P., 2006. Endogeneous Leadership in Teams. Journal of Institutional and Theoretical Economics 162, 253-61.

Jensen, M.C., 2005. Leadership. Harvard NOM Research Paper, 06-05.

Judge, T.A., Bono, J.E., Ilies, R., Gerhardt, M.W., 2002. Personality and Leadership: A Qualitative and Quantitative Review. Journal of Applied Psychology 87(4), 765-80.

Kumru, C., Vesterlund, L., 2005. The Effects of Status on Voluntary Contribution. University of Pittsburgh, mimeo.

Kurzban, R., Houser, D., 2005. Experiments investigating cooperative types in humans: A complement to evolutionary theory and simulations. Proceedings of the National Academy of Sciences of the United States of America 102(5), 1803-7.

List, J.A., Lucking-Reiley, D., 2002. The Effects of Seed Money and Refunds on Charitable Giving: Experimental Evidence from a University Capital Campaign. Journal of Political Economy 110, 215-33.

Meidinger, C., Villeval, M.C., 2003. Leadership in Teams: Signaling or Reciprocating? GATE Working Paper, 10-03. Lyon.

Moxnes, E., van der Heijden, E., 2003. The Effect of Leadership in a Public Bad Experiment. Journal of Conflict Resolution 47(6), 773-95.

Potters, J., Sefton, M., Vesterlund, L., 2005. After You - Endogenous Sequencing in Voluntary Contribution Games. Journal of Public Economics 89, 1399-419. , 2007. Leading-by-example and signaling in voluntary contribution games: An experimental study. Economic Theory, forthcoming.

Rolland, J.P., Parker, W., Stumpf, H., 1998. A Psychometric Examination of the French Adaptation of the Neo-Pir and Neo-Ffi. Journal of Personality Assessment 71(2), 269-91. 
Rossier, J., DeFruyt, F., Rolland, J.P., 2003. Psychologie De La Personnalité. Sprimont: Mardaga.

Shang, J., Croson, R., 2007. The impact of social comparisons on non-profit fundraising. Research in Experimental Economics, forthcoming.

Silverman, W., Robertson, S., Middlebrook, J., Drabman, R., 1984. An Investigation of Pledging Behavior to a National Charitable Telethon. Behavior Therapy 15, 304-11.

Sugden, R., 1984. Reciprocity: The Supply of Public Goods through Voluntary Contribution. Economic Journal 97, 772-87.

Terman, L.M., 1904. A Preliminary Study in the Psychology and Pedagogy of Leadership. Journal of Genetic Psychology 11, 413-51.

Titmuss, R.M., 1970. The Gift Relationship. London: Allen and Unwin.

Varian, H.R., 1994. Sequential Provision of Public Goods. Journal of Public Economics 53, $165-86$.

Vesterlund, L., 2003. Informational Value of Sequential Fundraising. Journal of Public Economics 87, 627-57.

Zeiliger, R., 2000. A Presentation of Regate, Internet Based Software for Experimental Economics. http://www.gate.cnrs.fr/ zeiliger/regate/RegateIntro.ppt., GATE. 


\section{NOTES}

${ }^{1}$ Explaining why blood donations might be adversely influenced by the introduction of material incentives (as shown by Titmuss (1970). Arrow (1972) suggests that charitable behavior may be motivated not merely by a desire to increase someone else's welfare, "but from the fact that the individual himself has contributed to that satisfaction,” (p. 348). These approaches highlight the fact that individual may be interested in what others think, bearing close resemblance to the model of Benabou and Tirole (2006) in which individuals are concerned with maintaining a positive social image in their reference group.

${ }^{2}$ Allowing several leaders would pose an empirical challenge of measuring their influences in our simple setup. For example, with two leaders with different contributions and attributes, it is not clear which one of the two leaders have a greater influence on the third member. Our design also has advantage of allowing us to study the revision of contributions between the two stages by eliminated leader candidates. As will become clearer later, this helps us identify what motivates some subjects to become the leader.

3 The choice of the number of attributes is directed by the willingness to characterize an individual without putting his anonymity into question. The choice of the attributes is driven by the same considerations.

4 The charities were Handicap International (http://www.handicap-international.org/), Médecins sans Frontières (http://www.msf.org/), and the United Nations Children's Fund (UNICEF) (http://www.unicef.org/). We offered the choice between three NGOs to avoid that some subjects refuse to donate not because of the idea of giving up money but because they dislike a specific organization.

${ }^{5}$ The amount of the donation is not displayed to avoid that people recognize another player after several repetitions.

${ }^{6}$ A subject's neuroticism score helps us distinguish individuals with low self-esteem from those who are calm. The extraversion score opposes outgoing and talkative subjects to inhibited persons while the openness score distinguishes original from conservative subjects. Agreeableness contrasts trusting and forgiving individuals to rude ones. Conscientiousness distinguishes reliable from disorganized subjects.

${ }^{7}$ A high number of successive identical responses is considered as raising doubt on whether the subject answered trustfully. We did not find such cases in our sample, each questionnaire has therefore been used.

87 sessions involved 18 subjects and 1 session involved 15 participants.

${ }^{9}$ Only a small minority of these students is working. Asking the participants whether they have a job is not informative. Asking about the parents' income gives typically a low response rate. Ownership of a car is an imperfect but indicative measure of resources. $61 \%$ of the participants own personally a car $(64 \%$ of the females and $58 \%$ of the males). A two-sample test of proportion accepts the null hypothesis of no difference between the proportion of car owners among females and males $(\mathrm{p}=0.47)$.

${ }^{10}$ The greater conditionality of females' decisions has been observed with respect to the attitudes towards competition (see Gneezy, Niederle and Rustichini, 2003).

${ }^{11}$ In BIB sequences, in which it is common knowledge that no information about donation will be revealed, females donate an average of 73.60 points while males donate much less, an average of 55.38 points. This difference vanishes in other sequences, where it is common knowledge that donation information is to be made public. In BAB and ABA sequences, females donate 97.02 and males 91.16 points.

12 The Exogenous treatment is only played in periods 11 to 20. If we only consider these periods, we still observe that the proportions of leaders who contribute nothing are $6 \%$ in the Benchmark and $5 \%$ in the Attribute treatments; the proportions who contribute their full endowment are $38 \%$ and $33 \%$, respectively.

${ }^{13}$ We do not have enough independent observations to use systematic non parametric statistics. An imperfect alternative is to use the data from the first three rounds of the pooled endogenous treatments given that most people are teamed with new subjects in the beginning of the game. Mann-Whitney U tests conducted under these conditions reject the null hypothesis of no difference between the contributions of an eliminated candidate and a (self-selected) follower for both females $(\mathrm{p}=0.006)$ and males $(\mathrm{p}=0.022)$. 
${ }^{14}$ Mann-Whitney U tests conducted under the same conditions mentioned in the previous note accept the null hypothesis of no difference between an actual leader's contribution and an eliminated candidate's revised contribution $(\mathrm{p}=0.385)$ for females but reject it for males $(\mathrm{p}=0.009)$.

15 We apply the hierarchical Wald method based on the minimization of the intra-group variance $\left(\sum_{k=1}^{p}\left(x_{k i}-x_{k j}\right)^{2}\right)$ to identify the clusters. 
Table 1. Ordering of treatments in the experimental sessions

\begin{tabular}{ccccc}
\hline Periods 1-10 & Periods 11-20 & Periods 21-30 & Nb sessions & Nb sujets \\
\hline Benchmark & Attribute & Benchmark & 3 & 54 \\
Attribute & Benchmark & Attribute & 2 & 36 \\
Benchmark & Imposed-leader & Benchmark & 3 & 51 \\
\hline
\end{tabular}


Table 2. Summary descriptive statistics

\begin{tabular}{|c|c|c|c|}
\hline Treatment & Benchmark & Attribute & Imposed-leader \\
\hline Number of observations & 2460 & 1260 & 510 \\
\hline $\begin{array}{l}\text { Number of leaders (\%) } \\
\% \text { of groups with leader }\end{array}$ & $\begin{array}{l}618(25.12) \\
56.46\end{array}$ & $\begin{array}{c}336(26.67) \\
59.29\end{array}$ & $\begin{array}{c}170(33.33) \\
100\end{array}$ \\
\hline Groups with a leader (averages) & & & \\
\hline $\begin{array}{l}\text { Candidate's contribution } \\
\text { Actual leader's contribution } \\
\text { Actual follower's contribution } \\
\text { Size of the public good } \\
\text { Leader's payoff } \\
\text { Follower's payoff }\end{array}$ & $\begin{array}{l}11.97(6.65) \\
11.84(6.71) \\
5.52(6.89) \\
22.87(15.10) \\
19.46(4.69) \\
25.79(5.53)\end{array}$ & $\begin{array}{c}12.12(6.58) \\
11.84(6.61) \\
5.23(6.68) \\
22.29(14.36) \\
19.16(4.67) \\
25.77(5.48)\end{array}$ & $\begin{array}{c}- \\
9.65(7.39) \\
5.03(6.60) \\
19.71(16.28) \\
20.06(4.40) \\
24.69(5.30)\end{array}$ \\
\hline $\begin{array}{l}\text { Groups without a leader (averages) } \\
\text { Contribution } \\
\text { Size of the public good } \\
\text { Payoff }\end{array}$ & $\begin{array}{r}1.84(4.42) \\
5.51(9.25) \\
20.79(3.50)\end{array}$ & $\begin{array}{c}1.40(3.36) \\
4.19(6.61) \\
20.56(2.76)\end{array}$ & $\begin{array}{l}- \\
-\end{array}$ \\
\hline
\end{tabular}

Note: Standard deviations in parentheses. In the endogenous treatments, "number of leaders" indicates the number of candidates. 
Table 3. Evolution of leaders' and followers' contributions over time in groups with a leader

\begin{tabular}{lcccc}
\hline Periods & Treatments & $\begin{array}{c}\text { Average leader candidates' } \\
\text { contribution (1) }\end{array}$ & $\begin{array}{c}\text { Average followers' } \\
\text { contribution (2) }\end{array}$ & Ratio (1)/(2) \\
\hline Sequence B-A-B & & & \\
$1-10 \quad$ Benchmark & 12.30 & 6.92 & 1.78 \\
$11-20$ & Attribute & 12.05 & 4.84 & 2.58 \\
$21-30 \quad$ Benchmark & 10.01 & 3.73 & 2.68 \\
\hline Sequence & A-B-A & & & \\
$1-10 \quad$ Attribute & 12.54 & 6.44 & 1.95 \\
$11-20$ & Benchmark & 11.80 & 4.76 & 2.48 \\
$21-30$ & Attribute & 11.51 & 4.06 & 2.83 \\
\hline
\end{tabular}


Table 4. The decision to lead (random-effect probit models)

\begin{tabular}{|c|c|c|c|c|}
\hline \multirow{2}{*}{$\begin{array}{l}\text { Variable: } \\
\text { Leader choice }\end{array}$} & \multicolumn{2}{|c|}{ Endogenous treatments } & \multicolumn{2}{|c|}{ Attribute treatment } \\
\hline & Coefficient & Marginal effects & Coefficient & Marginal effects \\
\hline Attribute treatment & $\begin{array}{c}0.087 \\
(0.064)\end{array}$ & 0.024 & & \\
\hline Period & $\begin{array}{l}-0.034^{* * *} \\
(0.003)\end{array}$ & $-0.009 * * *$ & $\begin{array}{l}-0.033^{* * * *} \\
(0.006)\end{array}$ & $-0.009 * * *$ \\
\hline Gender (male=1) & $\begin{array}{c}0.384 * * \\
(0.181)\end{array}$ & $0.103^{* *}$ & $\begin{array}{r}0.394 \\
(0.283)\end{array}$ & 0.105 \\
\hline Donation & $\begin{array}{l}0.002^{* * *} \\
(0.001)\end{array}$ & $0.0006^{* * *}$ & $\begin{array}{l}0.003^{* *} \\
(0.001)\end{array}$ & $0.0007^{* *}$ \\
\hline Donation * Gender & $\begin{array}{l}-0.002^{*} \\
(0.001)\end{array}$ & $-0.0006^{*}$ & $\begin{array}{l}-0.003^{*} \\
(0.001)\end{array}$ & $-0.0008^{*}$ \\
\hline Donation * BIB & $\begin{array}{c}0.001 \\
(0.001)\end{array}$ & 0.0002 & & \\
\hline Car ownership & $\begin{array}{l}-0.143 \\
(0.159)\end{array}$ & -0.038 & $\begin{array}{l}-0.167 \\
(0.236)\end{array}$ & -0.043 \\
\hline Neuroticism & $\begin{array}{c}0.005 \\
(0.008)\end{array}$ & 0.001 & $\begin{array}{r}0.015 \\
(0.011)\end{array}$ & 0.004 \\
\hline Extraversion & $\begin{array}{l}-0.006 \\
(0.008)\end{array}$ & -0.002 & $\begin{array}{r}-0.015 \\
(0.012)\end{array}$ & -0.004 \\
\hline Openness & $\begin{array}{l}0.013 * \\
(0.007)\end{array}$ & $0.003^{*}$ & $\begin{array}{r}0.009 \\
(0.011)\end{array}$ & 0.002 \\
\hline Agreeableness & $\begin{array}{r}-0.009 \\
(0.008)\end{array}$ & -0.002 & $\begin{array}{l}-0.013 \\
(0.012)\end{array}$ & -0.003 \\
\hline Conscientiousness & $\begin{array}{c}0.011 \\
(0.008)\end{array}$ & 0.003 & $\begin{array}{c}0.012 \\
(0.012)\end{array}$ & 0.003 \\
\hline Matched with 2 low donors & & & $\begin{array}{l}-0.208^{* *} \\
(0.102)\end{array}$ & $-0.054 * *$ \\
\hline Matched with 2 high donors & & & $\begin{array}{c}0.222 \\
(0.158)\end{array}$ & 0.063 \\
\hline Matched with 2 females & & & $\begin{array}{l}-0.104 \\
(0.116)\end{array}$ & -0.027 \\
\hline Matched with 2 males & & & $\begin{array}{c}0.062 \\
(0.120)\end{array}$ & 0.016 \\
\hline Session dummies & Yes & & Yes & \\
\hline Constant & $\begin{array}{l}-1.581 \\
(1.004) \\
\end{array}$ & & $\begin{array}{c}-1.041 \\
(1.557) \\
\end{array}$ & \\
\hline Observations & & 720 & & 1260 \\
\hline Log-Likelihood & -17 & 26.992 & & 581.932 \\
\hline Wald $\chi^{2}$ & & 3.82 & & 57.60 \\
\hline $\operatorname{Prob}>\chi^{2}$ & & 000 & & 0.000 \\
\hline
\end{tabular}

Note: *** significant at the 0.01 level; ** at the 0.05 level; * at the 0.1 level. 
Table 5. Determinants of the leader candidate's contribution (random-effect tobit models)

\begin{tabular}{|c|c|c|c|}
\hline $\begin{array}{l}\text { Variable: leader } \\
\text { candidate’s contribution }\end{array}$ & All treatments & $\begin{array}{l}\text { Endogenous } \\
\text { treatments }\end{array}$ & $\begin{array}{l}\text { Attribute } \\
\text { treatment }\end{array}$ \\
\hline Period & $\begin{array}{l}-0.215^{* * *} \\
(0.027)\end{array}$ & $\begin{array}{l}-0.216^{* * *} \\
(0.026)\end{array}$ & $\begin{array}{l}-0.096 * * \\
(0.047)\end{array}$ \\
\hline Attribute treatment & $\begin{array}{l}1.348^{* *} \\
(0.640)\end{array}$ & $\begin{array}{l}1.308^{* *} \\
(0.606)\end{array}$ & \\
\hline $\begin{array}{l}\text { Imposed-leader } \\
\text { treatment }\end{array}$ & $\begin{array}{l}-1.418^{*} \\
(0.774)\end{array}$ & & \\
\hline Gender (=1 if male) & $\begin{array}{l}0.801 \\
(0.784)\end{array}$ & $\begin{array}{c}1.268 \\
(0.854)\end{array}$ & $\begin{array}{l}0.729 \\
(1.391)\end{array}$ \\
\hline Donation & $\begin{array}{l}0.006 \\
(0.004)\end{array}$ & $\begin{array}{c}0.006 \\
(0.004)\end{array}$ & $\begin{array}{c}0.007 \\
(0.006)\end{array}$ \\
\hline Donation*gender & $\begin{array}{l}-0.005 \\
(0.005)\end{array}$ & $\begin{array}{l}-0.006 \\
(0.006)\end{array}$ & $\begin{array}{c}0.006 \\
(0.010)\end{array}$ \\
\hline Donation*BIB & $\begin{array}{l}0.004 \\
(0.005)\end{array}$ & $\begin{array}{c}0.001 \\
(0.006)\end{array}$ & \\
\hline Car ownership & $\begin{array}{c}0.882 \\
(0.693)\end{array}$ & $\begin{array}{c}0.670 \\
(0.747)\end{array}$ & $\begin{array}{c}0.527 \\
(1.175)\end{array}$ \\
\hline $\begin{array}{l}\text { Matched with } 2 \text { low } \\
\text { donors }\end{array}$ & & & $\begin{array}{l}-2.774^{* * *} \\
(0.902)\end{array}$ \\
\hline $\begin{array}{l}\text { Matched with } 2 \text { high } \\
\text { donors }\end{array}$ & & & $\begin{array}{c}0.831 \\
(1.302)\end{array}$ \\
\hline Matched with 2 females & & & $\begin{array}{l}-0.471 \\
(0.968)\end{array}$ \\
\hline Matched with 2 males & & & $\begin{array}{l}-0.656 \\
(1.027)\end{array}$ \\
\hline Personality factors & Yes & Yes & Yes \\
\hline Session dummies & Yes & Yes & Yes \\
\hline Constant & $\begin{array}{c}14.707^{* * * *} \\
(3.918)\end{array}$ & $\begin{array}{c}16.012^{* * *} \\
(4.112)\end{array}$ & $\begin{array}{l}18.251^{* *} \\
(7.336)\end{array}$ \\
\hline Observations & 1124 & 954 & 336 \\
\hline Left censured obs. & 99 & 58 & 11 \\
\hline Right censured obs. & 332 & 294 & 114 \\
\hline Log-Likelihood & -2835.842 & -2407.131 & -851.533 \\
\hline Wald $\chi^{2}$ & 135.440 & 136.830 & 58.150 \\
\hline Prob $>\chi^{2}$ & 0.000 & 0.000 & 0.000 \\
\hline
\end{tabular}

Note: *** significant at the 0.01 level; ** at the 0.05 level; * at the 0.1 level. 
Table 6. Determinants of a revision of the eliminated candidates' contributions

\begin{tabular}{lcc}
\hline $\begin{array}{l}\text { Variable: revision of } \\
\text { contributions }\end{array}$ & Ordered probit model & GLS model \\
\hline Period & -0.002 & 0.027 \\
& $(0.009)$ & $(0.047)$ \\
Attribute treatment & 0.057 & -0.196 \\
& $(0.210)$ & $(1.018)$ \\
Actual leader's contribution & $0.073^{* * *}$ & $0.522^{* * *}$ \\
& $(0.013)$ & $(0.064)$ \\
Gender (=1 if male) & $-0.382^{* *}$ & $-2.520^{* * *}$ \\
& $(0.176)$ & $(0.950)$ \\
Donation & 0.001 & -.0001 \\
& $(0.001)$ & $(0.004)$ \\
Car ownership & 0.113 & 0.657 \\
& $(0.175)$ & $(0.975)$ \\
Personality Factors & Yes & Yes \\
Session dummies & Yes & Yes \\
Constant & & -4.324 \\
& & $(6.119)$ \\
\hline Observations & & \\
Log-Likelihood & -234.591 & 0.294 \\
$\mathrm{R}^{2}$ & $0.092(\mathrm{pseudo})$ & 89.540 \\
Wald $\chi^{2}$ & 51.040 & 0.000 \\
Prob $\chi^{2}$ & 0.000 & \\
\hline
\end{tabular}

Note: Ordered probit model with robust standard errors. ${ }^{* * *}$ significant at the 0.01 level, and ${ }^{* *}$ at the 0.05 level. 
Table 7. Determinants of the follower's contribution (Random-effects tobit models)

\begin{tabular}{|c|c|c|c|}
\hline \multirow{2}{*}{$\begin{array}{l}\text { Variable: Follower's } \\
\text { contribution }\end{array}$} & \multirow{2}{*}{$\begin{array}{l}\text { All treatments } \\
\text { With leader }\end{array}$} & \multicolumn{2}{|c|}{ Benchmark and Attribute treatments } \\
\hline & & All groups & With leader \\
\hline Period & $\begin{array}{l}-0.317^{* * *} \\
(0.030)\end{array}$ & $\begin{array}{l}-0.455^{* * *} \\
(0.027)\end{array}$ & $\begin{array}{l}-0.274 * * * \\
(0.030)\end{array}$ \\
\hline Attribute treatment & $\begin{array}{l}-0.332 \\
(0.703)\end{array}$ & $\begin{array}{l}-0.020 \\
(0.565)\end{array}$ & $\begin{array}{l}-0.425 \\
(0.678)\end{array}$ \\
\hline Imposed-leader treatment & $\begin{array}{c}0.679 \\
(0.773)\end{array}$ & & \\
\hline Leader in group & & $\begin{array}{l}6.476 * * * \\
(0.503)\end{array}$ & \\
\hline Leader's contribution & $\begin{array}{c}0.614^{* * * *} \\
(0.040)\end{array}$ & & $\begin{array}{l}0.589 * * * \\
(0.944)\end{array}$ \\
\hline Eliminated leader & & $\begin{array}{l}5.286 * * * \\
(0.786)\end{array}$ & $\begin{array}{l}5.244^{* * *} \\
(0.707)\end{array}$ \\
\hline Gender (=1 if male) & $\begin{array}{l}1.183^{*} \\
(0.691)\end{array}$ & $\begin{array}{l}0.176 \\
(0.634)\end{array}$ & $\begin{array}{c}0.213 \\
(0.753)\end{array}$ \\
\hline Donation & $\begin{array}{l}0.014^{* * *} \\
(0.004)\end{array}$ & $\begin{array}{l}0.010^{* * *} \\
(0.003)\end{array}$ & $\begin{array}{l}0.009 * * \\
(0.004)\end{array}$ \\
\hline Donation*gender & $\begin{array}{l}-0.009 * * \\
(0.005)\end{array}$ & $\begin{array}{l}-0.007^{*} \\
(0.004)\end{array}$ & $\begin{array}{l}-0.007 \\
(0.005)\end{array}$ \\
\hline Donation*BIB & $\begin{array}{c}0.005 \\
(0.005)\end{array}$ & $\begin{array}{l}0.010^{* *} \\
(0.005)\end{array}$ & $\begin{array}{c}0.009 \\
(0.007)\end{array}$ \\
\hline Car ownership & $\begin{array}{l}-0.192 \\
(0.600)\end{array}$ & $\begin{array}{c}0.236 \\
(0.538)\end{array}$ & $\begin{array}{l}-0.080 \\
(0.642)\end{array}$ \\
\hline $\begin{array}{l}\text { Personality factors } \\
\text { Session dummies }\end{array}$ & $\begin{array}{l}\text { Yes } \\
\text { Yes }\end{array}$ & $\begin{array}{l}\text { Yes } \\
\text { Yes }\end{array}$ & $\begin{array}{l}\text { Yes } \\
\text { Yes }\end{array}$ \\
\hline Constant & $\begin{array}{l}-0.629 \\
(4.001)\end{array}$ & $\begin{array}{c}3.781 \\
(3.590)\end{array}$ & $\begin{array}{c}0.110 \\
(4.273)\end{array}$ \\
\hline $\begin{array}{l}\text { Observations } \\
\text { Left censured obs. } \\
\text { Right censured obs. } \\
\text { Log-Likelihood }\end{array}$ & $\begin{array}{c}1764 \\
854(48 \%) \\
171(10 \%) \\
-3538.451\end{array}$ & $\begin{array}{c}3008 \\
1906(63 \%) \\
180(6 \%) \\
-4699.990\end{array}$ & $\begin{array}{c}1424 \\
678(48 \%) \\
148(10 \%) \\
-2856.810\end{array}$ \\
\hline $\begin{array}{l}\text { Wald } \chi 2 \\
\text { Prob }>\chi 2\end{array}$ & $\begin{array}{c}448.380 \\
0.000\end{array}$ & $\begin{array}{c}702.860 \\
0.000\end{array}$ & $\begin{array}{c}394.870 \\
0.000\end{array}$ \\
\hline
\end{tabular}

Note: *** significant at the 0.01 level, and ${ }^{* *}$ at the 0.05 level. 
Table 8. Cluster analysis

\begin{tabular}{lcccrr}
\hline & Cluster 1 & Cluster 2 & Cluster 3 & Cluster 4 & All subjects \\
\hline $\begin{array}{l}\text { Relative frequency of the } \\
\text { decision to lead }\end{array}$ & 18.60 & 20.33 & 28.14 & 43.72 & 25.77 \\
Mean 1st stage contribution & 4.83 & 18.49 & 10.90 & 16.91 & 10.62 \\
Mean 2nd stage contribution & 1.62 & 1.47 & 4.10 & 8.54 & 3.91 \\
\hline Mean donation & 67.37 & 16.00 & 86.67 & 116.92 & 83.40 \\
\hline Number of observations & $38(27 \%)$ & $5(4 \%)$ & $60(43 \%)$ & $26(18 \%)$ & 141 \\
\hline
\end{tabular}




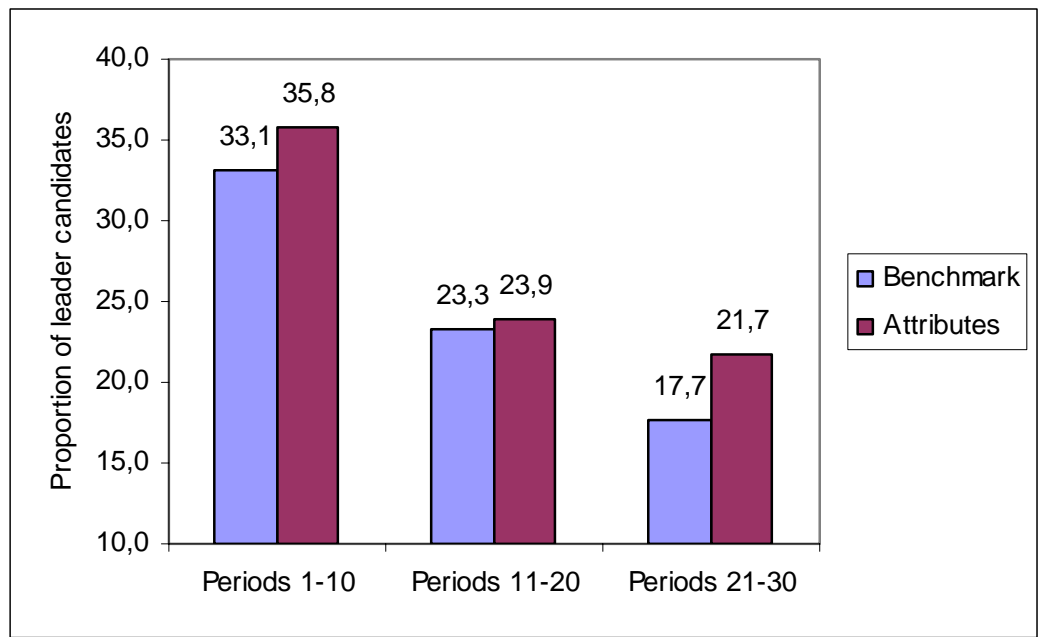

Fig.1. Evolution of the proportion of leader candidates by treatment 


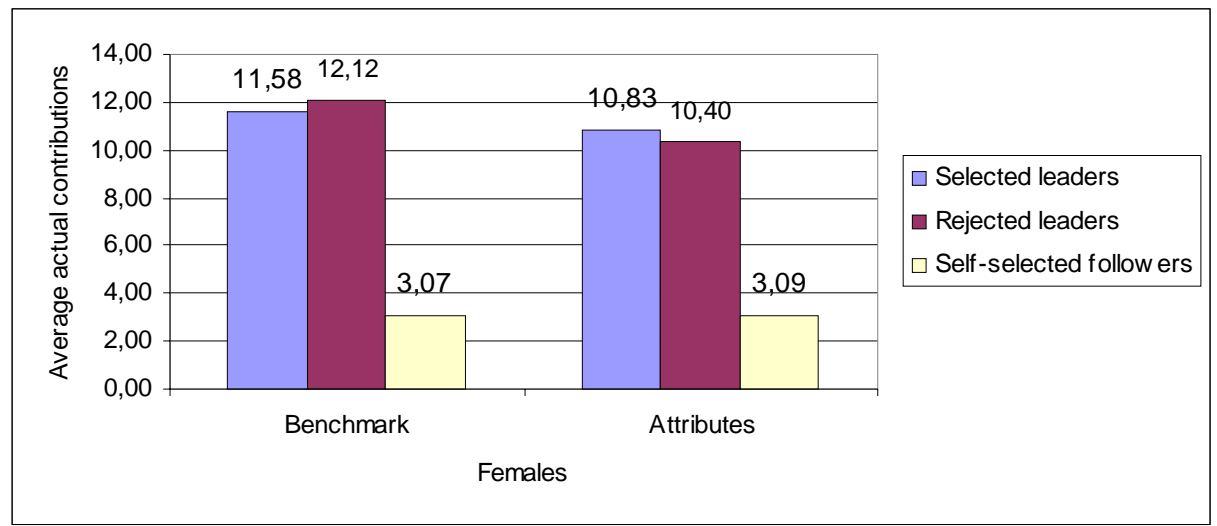

Fig.2a. Average actual contributions of females in the endogenous treatments

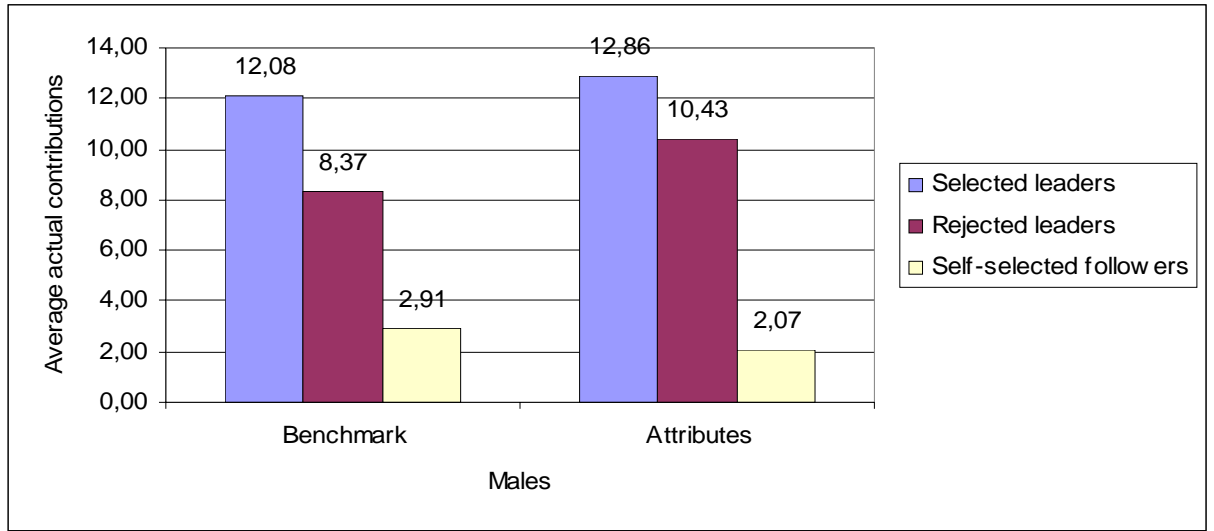

Fig.2b. Average actual contributions of males in the endogenous treatments 


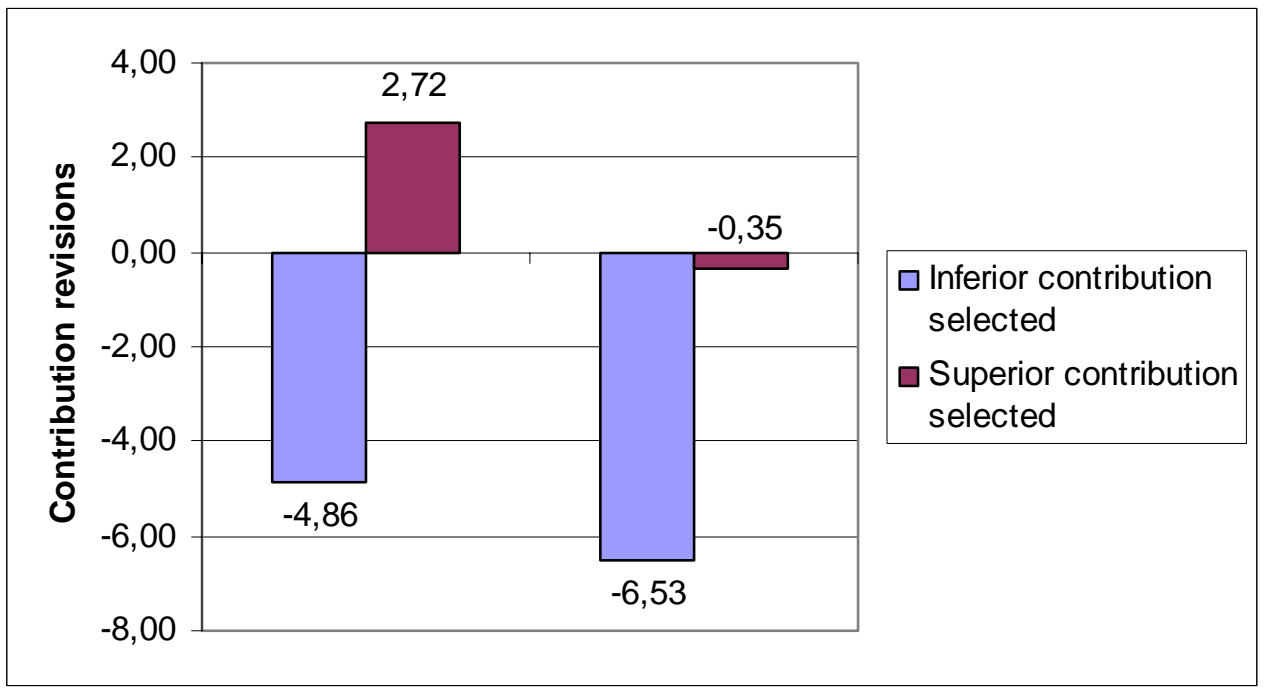

Females

Males

Fig.3. Revision of contributions by eliminated leaders in the endogenous treatments according to the actual leader's relative contribution 


\section{APPENDIX. Instructions for the Benchmark - Attributes - Benchmark sessions (other instructions available upon request)}

You are now taking part in an experiment on decision-making. During this experiment, your earnings depend on your decisions and the decisions of others. It is therefore important that you read these instructions with care.

In most cases, the amounts evoked during this experiment are expressed in points. The conversion rate of points into Euros is:

$$
80 \text { points }=1 \text { Euro }
$$

During this session, your earnings in points will be put on your account, cumulated and converted to Euros. The total amount of the compensation you will receive is confidential. It will be paid in cash in private in a separate room by a person who is not aware of the content of this experiment.

All your decisions are anonymous.

This session is divided into four parts. The instructions relative to the parts 2 to 4 will be distributed later.

Before starting the first part, we give you a show-up fee of $€ 6$. With this show-up fee, you can put Euros on your account and make a donation to a charitable organization.

- You can put Euros on your account. The amount of the show-up fee that you put on your account will be added to your earnings made during this session and paid to you in cash at the end of the session.

- You can make a donation to a charitable organization, among the three following: Handicap International, Médecins sans Frontières, ou UNICEF. You can find a description of each of these organizations in Appendix to these instructions.

If so, your donation will be made in private at the end of the session in a box in the payment room in presence of a person who is not aware of the content of this experiment.

We commit on our honor to give the entirety of these donations to these organizations. If you want to receive personally a receipt justifying the payment of all the donations to the three associations, please fill out the form attached to these instructions.

To make your decision, you are required to click one of the combinations displayed on your screen (from $€ 0$ for the donation and $€ 6$ put on your account, to a $€ 6$ donation and $€ 0$ put on your account). If you have chosen to make a donation, you will then indicate whom of the three organizations you want to give your donation to.

The information on your donation can be disseminated, anonymously, to the other participants during this session, as follows:

* A yellow disc indicates that your donation is higher than the average donation made by the participants to this session.

* A grey disc indicates that your donation is equal to or lower than the average donation made by the participants to this session.

You will also be requested to indicate your gender. This anonymous information is also liable to be disseminated to the other participants during the session. In all cases, you will be informed in the instructions preliminary to the dissemination of these pieces of information.

\section{First Part}

This part consists of 10 periods. The participants are divided into groups of three. In each new period, the composition of your group is modified randomly.

\section{Decision-making in each period}

The three members belonging to a group can participate in a project, by constituting an amount that will be shared equally among them. This amount results from the individual contributions of the three group members. 
In the beginning of each period, you receive an endowment of 20 points.

Each period consists of two stages.

- In the first stage, you decide if you are willing to make your contribution decision immediately or if you prefer to wait for the second stage.

Make your decision immediately means that you choose in the first stage the amount of your contribution to the project. This amount can take any possible value between 0 and 20 points.

The two other group members are informed on this contribution before making their own contribution decisions in the second stage.

In the group, only one member can contribute in the first stage. Three cases can occur.

$>$ 1st case: only one member has chosen to make his contribution decision in the first stage. The procedure described above applies.

$>2^{\text {nd }}$ case: more than one member in the group have chosen to make their contribution decisions in the first stage. A random draw determines the one whose contribution is taken into account. This random draw is independent on the chosen amount. The one or those who have not been randomly drawn are informed; their first stage contribution is not accounted for and the other group members are not informed about this contribution; they move to the second stage and they can modify the contribution they had previously indicated. Only those who were involved in the random draw and have not been drawn are informed about the existence of this random draw.

$>3^{\text {rd }}$ case: no member in the group has decided to contribute in the first stage. The three group members move directly to the second stage.

a In the second stage, after being informed of the contribution made by the member who has made his decision in the first stage, if any, the group members who have not decided in the first stage choose simultaneously the amount of their endowment they contribute to the project, i.e. any value between 0 and 20 points.

After all members have made their decisions, each one in the group is informed about the amount of each member's contribution in the second stage, the total amount of the project and his own payoff for the current period.

\section{Calculation of your payoff in each period}

- Your income consist of two parts:

$>$ the amount of your endowment which you have kept for yourself (i.e. 20 points - your contribution to the project),

$>$ your income from the project: this income represents half of the total contribution of all 3 group members to the project, whatever your personal contribution. In other words, we increase the amount of the project by $50 \%$ of the contributions and the total amount of the project is shared equally among the members of the group.

Your total income is therefore calculated by the computer program as follows:

(20 points - your contribution to the project)

$+50 \%$ (total contributions to the project)

The income of each group member is calculated in the same way, this means that each group member receives the same income from the project.

For example, suppose the total contributions of all group members is 40 points. In this case each member of the group receives an income from the project of $1 / 2(40)=20$ points. If the total contribution to the project is 5 points, then each member of the group receives an income of $1 / 2(5)=2.5$ points from the project.

For each point of your endowment that you keep for yourself you earn an income of 1 point. For every point you contribute to the project instead, the total contribution rises by one point. Your income from the project would rise by $1 / 2(1)=0.5$ point. The income of the other group members would however also rise by 0.5 point each, so that the total income of the group from the project would rise by 1.5 point. Your 
contribution to the project therefore also raises the income of the other group members. On the other hand you earn an income for each point contributed by the other members to the project. For each point contributed by any member you earn $1 / 5(1)=0.5$ point.

It is prohibited to communicate with the other participants during the experiment. If you violate this rule, you will be excluded from the experiment and from payments.

If you have any question regarding these instructions, please raise your hand. We will immediately answer to your questions in private.

\section{Second Part}

[These instructions were distributed at the end of the first 10 periods]

This part consists of 10 periods. The participants are divided into groups of three. In each new period, the composition of your group is modified randomly.

The rules for decision-making are the same as before, except for one thing.

In the beginning of each period, you are informed about the attributes of each member of your group and the other members of your group are informed about your attributes. These anonymous attributes are your gender and the color corresponding to your donation (a yellow disc for a donation above the average donation made in the session and a grey disc for a donation equal to or below the average).

Each contribution, made either in the first or in the second stage, is displayed on your screen beside these attributes.

The payoffs of each period are calculated like in the first part.

\section{Third Part}

[These instructions were distributed at the end of the first 20 periods]

This part consists of 10 periods. The participants are divided into groups of three. In each new period, the composition of your group is modified randomly.

During this part, the instructions are those in use during the first part.

\section{Fourth Part}

This fourth part consists of a questionnaire comprising 60 affirmations. Please read each of them carefully. For each item, please circle that of the five boxes which fits your opinion best:

Circle SD (Strongly Disagree) if the affirmation is quite wrong or if you strongly disagree.

Circle $\mathbf{D}$ (Disagree) if the affirmation is rather wrong or if you disagree.

Circle $\mathbf{N}$ (Neutral) if the affirmation is almost equally wrong or true or if you cannot choose or if have no opinion.

Circle A (Agree) if the affirmation is rather true or if you agree.

Circle SA (Strongly Agree) if the affirmation is quite true or if you strongly agree.

There is no "good" or "bad" answer. The aim of the questionnaire will be reached if you describe yourself and if you express your opinions as exactly as possible. Answer to each question. If you made a mistake or if you change your mind, do not erase. Put a $\mathrm{X}$ on the incorrect answer and circle the correct answer.

You will earn 2 additional Euros for filling this questionnaire out. Your answers are of course still anonymous and will never be communicated to anyone. I thank you for filling this questionnaire sincerely. 